\title{
How Does Advertising Appeal Affect the Attitude of Brand Intelligent Extension?
}

\author{
Wenjia $\mathrm{He}^{*}$ and Xiaodong Qiu
}

\author{
School of Economics and Management, Beijing Jiaotong University, China, 100044 \\ ${ }^{*}$ Corresponding author. Email: 19113069@bjtu.edu.cn
}

\begin{abstract}
Brand intelligent extension is an important strategy for enterprises to conform to the trend of The Times and realize long-term development. However, the launch of new products cannot be separated from the publicity and promotion of advertisements. Therefore, how to formulate advertising strategies for intelligent extension products has become an important issue. This study found that different advertising strategies should be adopted for different types of intelligent extension products through one study between $2 \times 2$ groups. (1) For prototype intelligent extension products, compared with warm advertising appeals, consumers have a more positive attitude towards competent advertising appeals; (2) For exemplar intelligent extension, consumers' attitudes towards competent or warm advertising appeals are at a high level, and there is no significant difference; (3) Pleasure and arousal play a mediating role, that is, the interaction between brand intelligent extension and advertising appeals has a positive impact on consumers' attitudes through pleasure and arousal. This study is of practical significance for enterprises to make effective advertising strategies for intelligent extension products.
\end{abstract}

Keywords: Brand intelligent extension, Advertising appeal, Brand attitude.

\section{INTRODUCTION}

The arrival of artificial intelligence has set off a wave of intelligent transformation. Many enterprises continuously launch intelligent products to meet consumers' new requirements of time-saving and efficient. Nowadays, enterprises carry out brand intelligent extension not only to meet the needs of consumers, but also to meet the needs of strategic adjustment and competition. On the one hand, in order to get rid of the traditional development dilemma and break the profit bottleneck, enterprises need to realize diversified management and carry out intelligent transformation. On the other hand, by launching smart products, enterprises can occupy the market and gain sustainable competitive advantages. Therefore, as an important marketing strategy, brand intelligent extension is related to the development quality of enterprises. Advertising promotion is indispensable for the launch of any new product, and intelligent extension products are no exception. Enterprises often use advertisements to establish the connection between the parent brand and extension products. Some studies have focused on the influence of advertising on brand extension attitude [1], however, the influence of different advertising types on brand extension attitudes has not been discussed, and the research on brand intelligent extension is still in the blank.

Reviewing the existing studies, the academia's research on brand extension attitude mostly adopts the classic paradigm, that is, to investigate consumers' attitude towards brand extension from the fit degree between the extended product and the parent brand, and it is generally believed that consumers are more likely to have a positive attitude in the context of high fit degree. In addition, advertising appeals tend to influence consumers' cognition and emotional behavior towards products. In the past, when classifying advertising appeals, scholars mainly focused on rational and emotional appeals, abstract and specific appeals, functional and experiential appeals, etc. In recent years, some scholars have introduced the stereotype content model, specifically dividing the advertising appeals into two types: competence and warmth, then whether the competent and warm advertising appeals have an impact on the brand's attitude towards intelligent extension? The answer to this question remains to be further explored. 
To sum up, the academia has not paid enough attention to the brand intelligent extension. This study intends to explore the influence of advertising appeals on the brand intelligent extension attitude by integrating the stereotype content model and brand extension theory from the new perspective mentioned above. The results of the research not only expand and enrich the brand extension theory, but also help enterprises to provide theoretical support to develop the advertising strategy of intelligent extension products.

\section{THEORETICAL BACKGROUND AND HYPOTHESIS DEVELOPMENT}

\subsection{Brand Intelligent Extension Type}

Brand extension is an important marketing strategy for enterprises to launch new product categories by virtue of the market influence of the original brands [2]. Successful brand extension can help enterprises maintain good reputation and create and continuously meet consumer demand, and it is also an important means for enterprises to accumulate brand assets and improve brand performance. With the advent of the era of big data and artificial intelligence, brand intelligent extension has become a kind of new enterprise development mode. However, there is still no clear definition of brand intelligent extension in the academic circles. In this study, brand intelligent extension refers to enterprises launch intelligent products with the help of mature brands with certain market influence, which can not only help enterprises quickly and effectively occupy the intelligent product market, but also deliver time-saving, efficient, scientific and technological life concepts to consumers.

The perceived fit between the product extension and the parent brand has been proved to be the core factor influencing consumers' attitude towards brand extension. The difference in the degree and type of fit between the extension product and the parent brand will also cause the difference in the mechanism and effect of the brand extension attitude. Referring to the classification method of brand extension type proposed by Mao and Krishnan [3], this study divides brand intelligent extension into prototype intelligent extension and exemplar intelligent extension. The former refers to the intelligent products which are consistent with the image and concept of the parent brand. The latter refers to an enterprise which, based on a specific product of its parent brand, launches an intelligent product with similar functions and attributes.

\subsection{Interaction Effect}

According to the stereotype content model, people make a comprehensive judgment on people or things mainly from the two dimensions of competence and warmth [4]. Aaker found that consumers' judgment of competence or warmth affects their purchase intention, loyalty and brand recommendation behavior, as well as consumers' attitude towards the brand and purchase behavior. In recent years, the stereotype content model has been applied to the field of branding. It emphasizes that consumers' perception of the brand can also be divided into two dimensions: competence and warmth. Advertising is an important carrier to influence consumers' perception of the brand, and the core information of the brand can be reflected through advertising appeals. Consumers are more likely to buy a product if they are generally positive about the advertising appeals. The types of advertising appeals often influence consumers' cognitive and emotional behaviors. Referring to the research of Puzakova [5], this paper divides the advertising appeals into the competence appeal and the warmth appeal. Competent appeal demands to show brand confidence, efficiency, talent, creativity and competitiveness in advertising messages, while warm appeal to show sincerity, friendship, warmth and cooperation.

In essence, exemplar intelligent extension does not break away from the existing product category. It carries out intelligent upgrading and transformation on the basis of a specific product under the parent brand, and its properties are consistent with the original product. According to the theory of extension matching degree, exemplar intelligent extension has a high match with the parent brand in both brand concept and category, and consumers will transfer their positive association of the parent brand to the intelligent extension, thus producing positive evaluation. In other words, high matching degree will not have a negative impact on consumers. According to this hypothesis, whether it is the confidence and creativity of the competent advertisement or the friendliness and sincerity of the warm advertisement, consumers have a positive evaluation of the exemplar intelligent extension. Prototype intelligent extension tries to launch intelligent products different from the existing types of the parent brand, but its brand image and concept are consistent with the parent brand. Consumers often have consumption concerns about the new product categories launched by the brand. Although the prototype intelligent extension is highly consistent with the parent brand in terms of brand concept, it is a low match in terms of category. As consumers become more rational, they pay more attention to the substantive function, value and creativity of the products when buying prototype intelligent products, and tend not to make impulsive purchasing decisions based on the positive image of the brand. The information displayed by competent advertisements can convey confidence, efficiency, talent, creativity and competitiveness of the brand, and to a certain extent, gain consumers' trust and 
dispel doubts. Therefore, this study proposes the following hypothesis:

H1: For prototype intelligent extension, competent (vs. warm) advertising appeals have a more positive impact on brand attitude; For exemplar intelligent extension, there is no significant difference between the two types of advertising appeal on brand attitude.

\subsection{The Mediating Effect of Pleasure and Arousal}

Brand intelligent extension tends to add intelligent elements into the parent brand, so it has the characteristics of digitization and informatization. The huge contrast with previous products will bring emotional changes to consumers to some extent. Pleasure and arousal are two core components of the emotional experience. Pleasure refers to the degree to which people feel happy, satisfied, while arousal refers to the degree to which people feel excited, alert, stimulated, aroused, awakened and positive in the situation. Information processing fluency theory also points out that consumers' information processing fluency comes from the matching between advertising appeals and brand intelligent extension types. A high degree of matching can improve the degree of information processing fluency, and then awaken consumers' inner pleasure and make positive comments. When individuals are in a positive emotional state, they are more likely to make positive judgments about people or things. According to the stimulus-organicresponse theory of environmental psychology, individuals will make corresponding behavioral responses when stimulated by the external environment. The S-O-R model is applied to consumers' recognition of advertising appeals. The matching effect of brand intelligent extension and advertising appeals can make individuals feel happy and arouse their emotions. Consumers are more inclined to make positive comments on brand intelligent extension. Therefore, this paper proposes the following hypothesis:

$\mathrm{H}$ 2: Pleasure and arousal have a positive effect on brand intelligent extension attitude.

H3: Pleasure and arousal can mediate the influence of the interaction between brand intelligent extension type and advertisement appeal on brand attitude.

To sum up, this study will focus on the influence of the interaction between brand intelligent extension type and advertising appeal on brand attitude, and also examine the mediating effect of pleasure and arousal. The research framework is shown in Figure 1. In this study, the stimulus materials needed for subsequent study was selected through preliminary study. One formal study was designed to control the appeal of advertisements by changing the background color of advertisements, in order to test the robustness of the theoretical framework of this study.

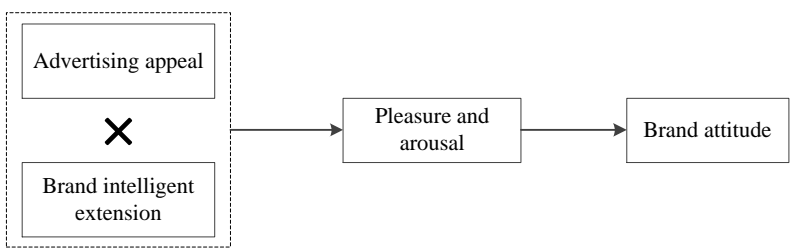

Figure 1 Research Framework.

\section{STUDY}

\subsection{Preliminary Study}

We chose Adidas as the parent brand for the study for the following reasons: (1) the brand has a good image and enjoys a high degree of familiarity; (2) the brand has a clear line of extension; (3) the brand is trying to launch smart products in recent years. A total of 31 MBA students participated in this test. The subjects reported their familiarity with Adidas $(\mathrm{M}=5.82)$ and their preference $(M=5.16)$. The results showed that the subjects had a relatively positive attitude towards the brand image of Adidas.

In order to determine the stimulus material needed for the study, we invited a professor who majors in marketing, three doctoral students, and two master's students, through literature review, brainstorming. Finally we chose the intelligent sports bracelet, intelligent running machine, intelligent body fat meter as the prototype extension products (consistent with the brand concept of health and sports of Adidas), the intelligent clothes, intelligent football and intelligent shoes as exemplar extension products (Share the same features or attributes with Adidas products). We recruited 30 undergraduates as subjects in a university of Beijing (male $53 \%, \mathrm{M}_{\mathrm{age}}=20.28$ ), and the participants were asked to rate how well the six smart extensions of the Adidas brand fit into the Adidas brand concept ( $1=$ not at all, $7=$ to a great extent) and how similar they were to its products $(1=$ not at all, $7=$ to a great extent). The results showed that the smart sports bracelet has the highest degree of consistency with the brand concept $(M=5.72)$, and the smart running shoes were the most similar to the brand's products. $(\mathrm{M}=5.87)$.

Next, we select the intelligent sports bracelet as the prototype intelligent extension product, and the intelligent football as the exemplar intelligent extension product, and conduct the control inspection. 35 undergraduates (male $48 \%, \mathrm{M}_{\mathrm{age}}=21.07$ ) were recruited from a university in Beijing to participate in the study. The subjects were randomly assigned to the prototype intelligent extension group and the exemplar intelligent extension group. The reading materials of the subjects in the prototype intelligent extension group were as follows: "In order to conform to the trend of the age of artificial intelligence, Adidas has launched an intelligent 
sports bracelet. The bracelet uses photoelectric heart rate sensor, which can intelligently monitor the heart rate, exercise intensity and elasticity and provide allround tracking for healthy exercise." The reading materials of the exemplar intelligent extension group were: "In order to adapt to the trend of the age of artificial intelligence, Adidas has launched a pair of intelligent running shoes, which use a special magnetic sensor, which can intelligently adjust the strength of the sole shock absorption system, providing the best buffer for healthy exercise." The participants then rated how closely the two products aligned with the Adidas brand and how similar they were to its products. The data showed that the intelligent sports bracelet had a higher degree of brand consistency with Adidas $\left(\mathrm{M}_{\text {bracelet }}=5.62\right.$ vs. $\left.\quad \mathrm{M}_{\text {shoes }}=2.21, \mathrm{t}(34)=13.901, \mathrm{p}<0.001\right)$. Intelligent running shoes are more similar to Adidas products $\left(\mathrm{M}_{\text {bracelet }}=5.74\right.$ vs. $\quad \mathrm{M}_{\text {shoes }}=2.26, \mathrm{t}(34)=18.104$, $\mathrm{p}<0.001)$. This result indicates that the manipulation of intelligent extension type is successful.

\subsection{Formal Study}

For this study, we adopted the form of print advertisement composed of copy writing and pictures, and the competent/warm advertising appeals are mainly controlled by different background colors and advertising slogans. Referring to existing studies, blue is used as the background color for competent advertisements, and yellow is used as the background color for warm advertisements. According to the twochannel cognitive theory, people's reading of advertisements is a process of continuous conversion between words and pictures. If the pictures and texts are consistent, it will be beneficial for learners to integrate information and produce a good learning effect. Therefore, we match the slogan "Adidas intelligent bracelet/running shoes, your health expert" with the competent advertisement appeal, and "Adidas intelligent bracelet/running shoes, protect your health" with the warm advertisement appeal. In order to avoid the interference of the advertising design on the study results, the two ads were required to adopt the same layout (such as the same plane size and font).

\subsubsection{Study Program}

In Study, 2(brand intelligent extension type: prototype intelligent extension vs. exemplar intelligent extension $) \times 2$ (competent advertising appeal vs. warm advertising appeal) intergroup factor design was adopted. A total of 163 universities students in Beijing participated in the study $(53 \%$ male, $M=21.26$ years old). In the main study, participants read a brief introduction about the Adidas brand and then were told that Adidas had launched a new smart product. In the prototype intelligent extension group, the product is "intelligent sports bracelet". In the exemplar intelligent extension group, the product is "intelligent running shoes". Then, they were randomly assigned to the competent advertising appeal group and the warm advertising appeal group. The first part is the manipulation test of advertising demands, "to what extent do you agree that this new product is warm/sincere/kind?" $(\alpha=0.932)$, the item for the competent advertising appeal is "To what extent do you agree that this new product is capable/efficient/competent?" $(\alpha=0.924)$. The second part is the measurement of consumers' pleasure and arousal, mainly referring to the study of Mehrabian and Russell ( $\alpha=0.919)$. The third part measures consumers' attitude towards brand intelligent extension $(\alpha=0.881)$.

For this study, we adopted the form of print advertisement composed of copy writing and pictures, and the competent/warm advertising appeals are mainly controlled by different background colors and advertising slogans. Referring to existing studies, blue is used as the background color for competent advertisements, and yellow is used as the background color for warm advertisements [6]. According to the two-channel cognitive theory, people's reading of advertisements is a process of continuous conversion between words and pictures. If the pictures and texts are consistent, it will be beneficial for learners to integrate information and produce a good learning effect. Therefore, we match the slogan "Adidas intelligent bracelet/running shoes, your health expert" with the competent advertisement appeal, and "Adidas intelligent bracelet/running shoes, protect your health" with the warm advertisement appeal. In order to avoid the interference of the advertising design on the study results, the two ads were required to adopt the same layout (such as the same plane size and font).

\subsubsection{Result Analysis}

(1) Control inspection. First, we tested the manipulation of advertising appeal types. The results showed that there were significant differences between the two types of advertising appeal types. In the context of stimulating materials, $\mathrm{M}_{\text {competence }}=5.09>\mathrm{M}_{\text {warmth }}=3.32$, $\mathrm{t}(162)=11.318, \mathrm{p}=0.000<0.001$. In the context of stimulating materials for warm advertisement demands, $\mathrm{M}_{\mathrm{c}}=3.24<\mathrm{M}_{\mathrm{w}}=5.28, \mathrm{t}(160)=14.427, \mathrm{p}=0.000<0.001$. It showed that the manipulation of advertising appeal type is successful.

(2) Brand attitude. In order to test the effect of the interaction between the type of intelligent extension and the advertising appeals on the brand attitude, we chose brand attitude as the dependent variable, the type of intelligent extension (prototype and exemplar) and the advertising appeals (competence and warmth) as the independent variables to make analysis of variance. The results showed that the main effect of the intelligent extension type was significant $[\mathrm{F}(1,159)=17.77$, 
$\mathrm{p}<0.001]$, the main effect of the advertising appeal was significant $[\mathrm{F}(1,159)=16.52, \quad \mathrm{p}<0.001], \quad$ and the interaction effect between the two was significant $[F(1,159)=11.069, \quad p=0.001]$. Further simple effect analysis is shown in Figure 2. For prototype intelligent extension, consumers' attitude towards competent appeals is significantly better than warm advertising appeals $\quad\left(\mathrm{M}_{\mathrm{p}-\mathrm{c}}=5.08, \quad \mathrm{M}_{\mathrm{p}-\mathrm{w}}=4.03, \quad \mathrm{~F}(1,77)=37.43\right.$, $\mathrm{p}<0.001)$. For exemplar intelligent extension, there was no significant difference in consumers' attitude towards brand extension in the two types of advertising appeals $\left(\mathrm{M}_{\mathrm{e}-\mathrm{c}}=5.19, \quad \mathrm{M}_{\mathrm{e}-\mathrm{w}}=4.96, \quad \mathrm{~F}(1,82)=1.695, \quad \mathrm{p}=0.197\right)$. Therefore, the hypothesis H1 is supported.

(3) Mediating effect. Boostrap method was used to test the mediation model with adjustment. We selected model 7, and the sample size was 5000. The results showed that, under the $95 \%$ confidence interval, the mediating test results did not include 0 (LLCI $=0.3096$, $\mathrm{ULCI}=0.8591$ ), and the mediating effect was $0.5697>0$, indicating that the mediating effect of pleasure and arousal was significant and positively affected the attitude of brand extension. In addition, after controlling the mediation variable pleasure and arousal, the independent variable no longer has a significant influence on the dependent variable (LLCI $=-0.1064$, $\mathrm{ULCI}=0.4941$ ). Thus, pleasure and arousal play a complete role in mediating effect, and the hypothesis that $\mathrm{H} 2$ and $\mathrm{H} 3$ are supported.

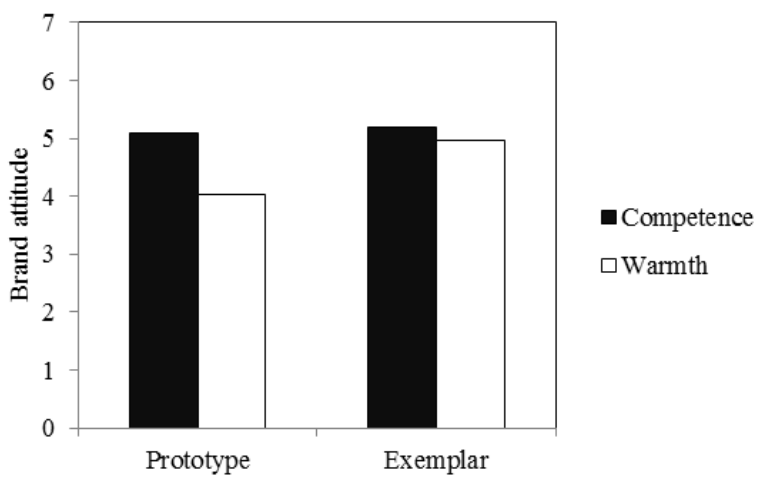

Figure 2 Interaction Effect.

\section{CONCLUSIONS AND IMPLICATIONS}

\subsection{Research Conclusions and Theoretical Contributions}

Based on the perspective of advertising and psychology, this study explored the influence of the interaction between two common types of brand extension and different advertising appeals on brand extension attitudes. The Study controlled the type of advertisement appeal by changing the background color of the advertisement, and also investigated the mediating effect of pleasure and arousal. The main conclusions are as follows: first, under the prototype intelligent extension, compared with the appeal of warm advertisement, consumers have a more positive attitude towards the appeal of competent advertisement; Under the exemplar intelligent extension, consumers' attitudes towards competent or warm advertisement appeals are at a high level, and there is no significant difference between them. Secondly, pleasure and arousal play a mediating role, that is, the interaction between brand intelligent extension and advertising appeals has a positive effect on consumers' attitude through pleasure and arousal.

Brand extension is an important research topic in product strategy, the theoretical contribution of this study has the following two aspects: first, based on the brand extension theory, this paper proposed the concept of brand intelligent extension for the first time, and discussed the influence of brand intelligent extension type on consumers' brand attitude from the interaction between brand intelligent extension type and advertising appeals. This broadens the research perspective and method of brand intelligent extension, and also provides theoretical support for enterprises to formulate intelligent extension advertising strategies and effectively improve consumers' attitudes. Second, previous studies on brand extension mostly used information processing fluency as a mediating variable. Through empirical research, this study found that pleasure and arousal can also play a mediating role in the interaction between brand intelligent extension and advertising appeals on brand attitudes, and positively influence consumers' attitudes. This result not only enriches the pleasure and arousal theory in the field of consumer behavior, but also provides a new way to explore brand extension in the future.

\subsection{Practical Implications}

In marketing practice, the conclusion of this study also provides a reference for enterprises to effectively implement the advertising strategy of intelligent extension products. When enterprises adopt different ways of advertising appeals for publicity, they should first pay attention to the evaluation of the intelligent extension type of the product, and judge whether it belongs to the prototype or the exemplar. Secondly, they should pay attention to the collocation and application of the advertising appeal and the intelligent extension type, that is, they should give full consideration to the perception of consumers. For prototype intelligent extension products, enterprises can use cool colors such as blue as the background color of advertising to improve consumers' attitude towards the brand. For exemplar brand intelligent extension products, using cool colors like blue or warm colors like yellow is appropriate. In addition, this study believes that advertising should not be limited to newspapers, magazines, leaflets, television, the Internet and other 
media, to some extent, product packaging also plays a role in advertising. For example, the enterprise can carry on the corresponding control to the intelligent extension product packaging color. So the conclusion of this study also has some reference significance for enterprises to design product packaging.

\section{AUTHORS' CONTRIBUTIONS}

Wenjia $\mathrm{He}$ designed experiments and wrote the manuscript. Xiaodong Qiu offered suggestions on amendments.

\section{ACKNOWLEDGMENTS}

The authors are grateful for the people involved in the study.

\section{REFERENCES}

[1] Hüttl. Verena, Gierl. Heribert, Can Advertising Elements Improve Consumer Evaluations of Brand Extensions with a Moderate or Low Fit? Psychology \& Marketing 28(2) (2011) 205-218. DOI: https://doi.org/10.1002/mar.20387

[2] D.A. Aaker, K.L. Keller, Consumer Evaluations of Brand Extensions, Journal of Marketing 54(1) (1990) 27 41. DOI: https://doi.org/10.1177/002224299005400102
[3] H. Mao, H.S. Krishnan, Effects of Prototype and Exemplar Fit on Brand Extension Evaluations: A Two-Process Contingency Model, Journal of consumer research 33(1) (2006) 41 49. DOI: https://doi.org/10.1086/504134

[4] S.T. Fiske, A.J.C. Cuddy, P. Glick, Universal Dimensions of Social Cognition: Warmth and Competence, Trends in Cognitive Sciences 11(2) (2007) 77 83. DOI: https://doi.org/10.1016/j.tics.2006.11.005

[5] Puzakova, M., Kwak, H., \& Bell, M. Beyond seeing McDonald's Fiesta menu: The role of accent in brand sincerity of ethnic products and brands, Journal of Advertising 44(3) (2015) 219 231. DOI: https://doi.org/10.1080/00913367.2014.957367

[6] L.I. Labrecque, G.R. Milne, Exciting red and competent blue: the importance of color in marketing, Journal of the Academy of Marketing Science 40(5) (2012) 711 727. DOI: https://doi.org/10.1007/s11747-010-0245-y 